\title{
BMJ Open Health and productivity burden of coronary heart disease in the working Indonesian population using life- table modelling
}

\author{
Regina E Uli, ${ }^{1,2}$ Regina P U Satyana, ${ }^{1,2}$ Ella Zomer, ${ }^{1}$ Dianna Magliano, ${ }^{1,3}$ \\ Danny Liew, ${ }^{1}$ Zanfina Ademi (1) ${ }^{1}$
}

To cite: Uli RE, Satyana RPU, Zomer $\mathrm{E}$, et al. Health and productivity burden of coronary heart disease in the working Indonesian population using life-table modelling. BMJ Open 2020;10:e039221. doi:10.1136/ bmjopen-2020-039221

- Prepublication history and additional material for this paper are available online. To view these files, please visit the journal online (http://dx.doi. org/10.1136/bmjopen-2020039221).

$\mathrm{DL}$ and $\mathrm{ZA}$ are joint last authors.

Received 09 April 2020 Revised 13 July 2020

Accepted 11 August 2020

Check for updates

(C) Author(s) (or their employer(s)) 2020. Re-use permitted under CC BY-NC. No commercial re-use. See rights and permissions. Published by BMJ.

${ }^{1}$ Department of Epidemiology and Preventive Medicine,

Monash University School of

Public Health and Preventive

Medicine, Melbourne, Victoria,

Australia

${ }^{2}$ University of Indonesia Faculty of Medicine, Jakarta, Daerah Istimewa Jakarta, Indonesia

${ }^{3}$ Baker IDI Heart and Diabetes Institute, Melbourne, Victoria, Australia

Correspondence to Professor Zanfina Ademi; zanfina.ademi@monash.edu

\section{ABSTRACT}

Objectives The impact of coronary heart disease (CHD) and its effect on work productivity at a population level remains unknown in Indonesia. This study estimates the health and productivity lost to $\mathrm{CHD}$ in terms of years of life, quality-adjusted life years (QALYS) and productivityadjusted life years (PALYS).

Setting and participants A life-table model was constructed to simulate the experiences of Indonesians currently aged 15-54 years (working age) with CHD, followed-up to 55 years (retirement age). The life-table analysis was then repeated assuming that the cohort did not have CHD. Differences in the results reflected the impact of CHD. Demographical, prevalence and mortality data were based on the 2017 Global Burden of Disease study and 2018 Indonesian National Health Survey. Costs, productivity indices and utilities were derived from published sources. The cost of each PALY was assumed to be equivalent to gross domestic product per equivalent full-time worker (US\$11 765). Future costs and outcomes were discounted by $3 \%$ annually.

Primary and secondary outcome measures Differences in total deaths, years of life and PALYs represented the impact of CHD.

Results At present, 1954543 (1.45\%) Indonesians of working-age have $\mathrm{CHD}$. By retirement age, it was estimated that $\mathrm{CHD}$ resulted in $32492(36.6 \%)$ excess deaths, $128132(0.5 \%)$ years of life lost, 2331495 (10.5\%) QALYs lost and 1589490 (6.9\%) PALYs lost. The economic impact of lost productivity amounted to US $\$ 33.3$ billion, and healthcare costs to US $\$ 139$ billion.

Conclusion The health and economic burden of $\mathrm{CHD}$ in Indonesia looms large. This highlights the importance of its prevention and control, strategies for which, if effective, will deliver financial return

\section{INTRODUCTION}

Coronary heart disease (CHD) is one of the major leading causes of death. ${ }^{1}$ The burden is rising in low-income to middle-income countries, including Indonesia. ${ }^{2}$ In 2018, Indonesia was the country with the second-highest number of disability-adjusted life years (DALYs) lost to CHD (130 per 1000 people). ${ }^{3}$
Strengths and limitations of this study

- We use 'productivity-adjusted life years' (PALYS), a recently developed metric which captures the economic burden of coronary heart disease.

- To estimate the cost of lost productivity, each PALY was ascribed the value of gross domestic product per equivalent full-time worker.

- Extensive scenario analyses were undertaken to test the robustness of the results.

- The life table assumption that age-specific mortality is assumed do not change over time.

- Data on projected prevalence were assumed to remain constant within the timeframe of the study.

This is $31 \%$ more than the mean DALYs lost in Organisation for Economic Co-operation and Development countries.

CHD is associated with reduced productivity in the working-age population, due to work days lost to ill health (absenteeism) and reduced efficiency at work (presenteeism). ${ }^{4}$ The resulting loss of productivity can impose an economic burden on individuals, employers and governments through reduced earnings, tax revenue and gross domestic product (GDP). In USA, an average of US $\$ 698$ is lost due to CHD per affected person due to short term disability. ${ }^{5}$ In Europe, CHD-related productivity losses amount to $€ 13953$ per person per year. ${ }^{6}$ In Indonesia, the percentage of productivity loss attributable to CHD due to absenteeism and presenteeism is estimated to be $2.8 \%$ and $6.8 \%$ of GDP per year, respectively. ${ }^{4}$

The above estimates are limited to shortterm periods. Estimates of productivity loss over longer-periods are important to capture the broader economic burden of CHD and to inform the case for investment in its prevention and control. 
In the present study, we sought to estimate the long-term impact of CHD on the Indonesian population in terms of years of life lost, quality-adjusted life years (QALYs) lost and productivity-adjusted life years (PALYs) lost due to CHD. PALYs are a novel measure of the productivity burden of disease and are akin to QALYs but adjust for impairment in productivity rather than quality of life.

\section{METHODS}

\section{Life-table modelling}

We used life-table modelling with a 1-year cycle length to estimate the health and productivity burden of CHD in Indonesia. Years of life, QALYs and PALYs lived were estimated for the cohort of Indonesians with CHD and of working age ( $15-55$ years).

To estimate cumulative years of life, QALYs and PALYs lost to CHD, the life-table model was reconstructed, but with the assumption that subjects hypothetically did not have CHD. The probabilities of death in each cycle were reduced to reflect the lesser risk of dying for people without CHD compared with those with the condition, while utilities and productivity indices were increased to reflect their higher quality of life and productivity, respectively.

The differences in the outputs of the two life tables, one each for that of the 'CHD cohort' and that of the hypothetical 'no CHD cohort' reflected the total years of life, QALYs and PALYs lost to CHD. Secondary analyses were undertaken with the assumption of reduction in the prevalence of CHD by $25 \%$ and $50 \%$. All results were presented in discounted values, based on the application of an annual discount rate of $3 \%$, as suggested by the Indonesian Health Technology Assessment Committee. ${ }^{7}$

To calculate PALYs, we multiplied years of life lived by 'productivity indices', in the same way, that utility indices (utilities) are used to 'weight' years of life lived to derive QALYs. The productivity index represents the productivity of an individual, ${ }^{8-12}$ and ranges from 0 (completely non-productive) to 1 (100\% productive).

\section{Patient and public involvement}

This is a modelling study, therefore patient and public were not involved.

\section{Data sources}

\section{Demographical profile and mortality}

The demographical profile of the Indonesian population and all-cause mortality used in the model was based on data from the Global Burden of Disease Study undertaken by the Institute for Health Metrics and Evaluation. ${ }^{13} 14$ Latest available data were from 2017, stratified by 5-year age group and sex. The population was further divided into cohorts with and without CHD. This was determined by multiplying prevalence CHD estimates for each age and sex group by their population sizes. ${ }^{15}$ All-cause death rates were computed for each age and sex stratum by dividing the number of all-cause deaths by the number of people within that stratum (online supplemental appendices 1 and 2).

To estimate mortality rates for age in single years, we first plotted mortality rates for each 5-year age group against the midpoint age for that age group (eg, 17 years for the age group 15-19 years). Polynomial functions were then applied in order to describe the relationships between age in single years and mortality risk (online supplemental appendix 3).

\section{Prevalence of coronary heart disease}

Prevalence data on CHD in Indonesia were sourced from the Indonesian National Health Survey Riset Kesehatan Dasar (RISKESDAS) for the year 2018. ${ }^{15}$ The data were stratified by age but not sex. However, the overall (nonage-specific) prevalence was reported for each sex. An assumption was made that within each 5-year age group, the same relative sex differential observed in the overall prevalence of CHD was applied.

To estimate prevalence estimates for age in single years, we first plotted prevalence for each 5-year age group against the midpoint age for that age group (eg, 17 years for the age group 15-19 years). Polynomial functions (which provided the best fit for the data, based on a $R^{2}$ which was closer to 1 ) were then applied in order to describe the relationships between age in single years and prevalence (online supplemental appendices 4 and 5).

\section{Mortality among the cohorts with and without coronary heart} disease

In order to derive mortality rates for the cohorts with and (hypothetically) without CHD, the following formulae were used:

$$
\begin{gathered}
R t=p \times R c+(1-p) \times R n c \\
R R=R c / R n c
\end{gathered}
$$

Where:

$R t=$ mortality risk in the total population (comprising people with and without CHD)

$p=$ prevalence of CHD

$R c=$ mortality risk in people with CHD

$R n c=$ mortality risk in people without CHD

$R R=$ relative risk of mortality among people with CHD compared with people without

Combining the two formulae led to:

$$
\begin{gathered}
R t=p \times R R \times R n c+(1-p) \times R n c \\
R t=R n c[p \times R R+(1-p)]
\end{gathered}
$$

This was then transposed to:

$$
R n c=R t /[p \times R R+(1-p)]
$$

Values for $R t$ and $p$ were known, as were estimates for $R R$. Hence for each age and sex stratum, values for $R n c$ and $R c$ could be calculated.

Relative risk (RR) data for all-cause mortality applicable to people with CHD compared with those without 
were obtained from a study by Norgaard et al on survivors of myocardial infarction. ${ }^{16}$ This was undertaken in 3092580 Danish subjects aged 30 years and above in the period from 1997 to 2006. The primary endpoints of the study were death by all causes, cardiovascular death and myocardial infarction (online supplemental appendix 6).

\section{Utility and productivity indices}

Utilities for the Indonesian general population for 2018 were derived from a study by Purba $e t$ al,${ }^{17}$ who used the EQ-5D tool on 1056 people from 17 to 75 years of age. The mean EQ-5D score in the whole population was 0.91 . The only study on utilities in South East Asian patients with CHD was undertaken by Nguyen $e t$ al in Vietnam, who found a mean EQ-5D score of 0.82 in this subpopulation. ${ }^{18}$ The utility of the Vietnamese general population was also 0.91 . Hence we assumed that utility data for Vietnamese people with CHD, available for age categories, also applied to Indonesians with CHD.

Productivity indices associated with CHD were based on relevant data on absenteeism (6.8 days/year) and presenteeism ( 15.0 days/year) as per the study by Goetzel et al. ${ }^{19}$ Data on absenteeism (3.6 days/year) and presenteeism (7.0 days/year) for a general population were obtained from a study conducted by Johns. ${ }^{20}$ The total working days missed in a year were quantified by combining days lost due to absenteeism and presenteeism, with the cohort with CHD assumed to missing 21.8 days per year $(6.8+15.0)$ and the general population missing 10.6 days per year $(3.6+7.0)$. Productivity indices were derived from dividing the total number of days worked in a year (maximum working days in a year subtracted by the total days missing of working days) by the maximum working days in a year.

To estimate the maximum working days per year in Indonesia, the overall percentage of equivalent full-time (EFT) workers was first identified using the following formula:

Number of full-time workers+((part-time weekly earnings/fulltime weekly earnings) *number of part-time workers).

Data on the number of people who worked part-time and full-time in Indonesia, including their corresponding monthly salaries, were acquired from the 'Labour Force Situation in Indonesia' and 'Income Statistics' data from Badan Pusat Statistik (BPS) in 2018, ${ }^{21}$ and were used to estimate EFT workers from age 15 to 55 years. The weighted average EFT workers aged 15-54 years in Indonesia was $83.2 \%$. Hence the maximum working days in a year within this age range was assumed to be 199.6 days, equivalent to 240 days ( 5 working days per week times 48 working weeks per year) multiplied by $83.2 \%$.

To derive productivity indices for the cohort with CHD and the general population, the number of total working days missed in a year (total days of absenteeism and presenteeism combined) was determined as a percentage of the maximum working days in a year for people aged 15-55 years (199.6 days). Thus, the cohort with CHD was estimated to have a productivity index of 0.891 ((199.6-21.8)/199.6), while the productivity index of a general population was estimated to be 0.947 ((199.6-10.6)/199.6).

\section{Cost of productivity loss}

The total costs of productivity loss attributable to CHD were based on the number of PALYs lost.

It was assumed that the cost of each PALY was equivalent to total GDP in Indonesia in 2019 (US\$1 179913 million or Indonesian Rupiah (IDR) 16837358510 million) divided by the number of EFT workers in Indonesia aged 15-55 years in 2018 (100 289529$).{ }^{21}{ }^{22}$ Hence the cost of each PALY was estimated to be US\$11 765 (IDR 168883 998), assuming that all GDP was produced by Indonesian workers aged $15-55$ years. A temporal trend in annual GDP growth of $5.17 \%$ was applied within the model's time horizon as per World Bank data. ${ }^{23}$

\section{Healthcare costs}

The total annual healthcare costs per person with CHD was acquired from the Indonesian Case Base Group for $2018,{ }^{24}$ and estimated to be US $\$ 5720$ (IDR 81620376 ). These costs covered those of community-based and hospital-based care, as well as those of treatments.

We assumed that the cohort hypothetically without CHD incurred no CHD-related healthcare costs. Key input data and summarised in table 1 .

\section{Scenario analyses}

A number of scenario analyses were undertaken to understand the uncertainty surrounding key input data on QALYs gained, PALYs lived and GDP lost owing to CHD. We assessed the impact of discounting, the RR of all-cause mortality associated with CHD, removing GDP temporal trends, halving the annual GDP growth rate and increasing the total annual number of missed workdays due to absenteeism and presenteeism from 21.8 to 25.07 days ( $15 \%$ increase).

\section{Patient and public involvement statement}

Patients or the public were not involved in the development or implementation of this study.

\section{RESULTS}

The prevalence of CHD in the Indonesian population of working-age was $1.45 \%$ (1.3\% in men and $1.6 \%$ in women), equating to almost 2.0 million people (865 855 men and 1.08 million women) aged between 15 and 55 years (retirement age) (table 1 ).

\section{Deaths}

Table 2 summarises the number of deaths from the cohort with CHD and the number of deaths that would have been avoided had the cohort not had CHD. With simulated follow-up until retirement (age 55 years), the cohort with CHD was predicted to incur 32492 excess deaths (15387 among men and 17105 among women). 
Table 1 The age-specific and sex-specific population and number of cohort with coronary heart disease aged 15-54 years in Indonesia in 2017

\begin{tabular}{|c|c|c|c|c|c|c|}
\hline \multirow[b]{2}{*}{$\begin{array}{l}\text { Five-year age } \\
\text { group }\end{array}$} & \multicolumn{3}{|l|}{ Men } & \multicolumn{3}{|l|}{ Women } \\
\hline & Population $^{1314}$ & $\begin{array}{l}\text { Prevalence of } \\
\text { coronary heart } \\
\text { disease }(\%)^{15}\end{array}$ & $\begin{array}{l}\text { Number with } \\
\text { coronary heart } \\
\text { disease }\end{array}$ & Population $^{1314}$ & $\begin{array}{l}\text { Prevalence of } \\
\text { coronary heart } \\
\text { disease }(\%)^{15}\end{array}$ & $\begin{array}{l}\text { Number with } \\
\text { coronary heart } \\
\text { disease }\end{array}$ \\
\hline $15-19$ & 11615900 & 0.46 & 52817 & 11186945 & 0.58 & 64202 \\
\hline $20-24$ & 10477601 & 0.56 & 57962 & 10345786 & 0.71 & 72876 \\
\hline $25-29$ & 10307565 & 0.71 & 72844 & 10207474 & 0.91 & 92367 \\
\hline 30-34 & 10433650 & 0.92 & 95489 & 10192667 & 1.18 & 119805 \\
\hline $35-39$ & 10339840 & 1.18 & 121876 & 10059746 & 1.52 & 152496 \\
\hline $40-44$ & 9589184 & 1.50 & 143569 & 9334423 & 1.93 & 179818 \\
\hline $45-49$ & 8455438 & 1.87 & 158176 & 8260705 & 2.41 & 198827 \\
\hline $50-54$ & 7094744 & 2.30 & 163122 & 7043260 & 2.96 & 208297 \\
\hline Total & 78313922 & 1.3 & 865855 & 76631005 & 1.6 & 1088688 \\
\hline
\end{tabular}

Table 2 Number of deaths and discounted years of life in the cohort with coronary heart disease and 'hypothetically' without coronary heart disease in Indonesians aged 15-54 years, followed up until the age of 55 years

\begin{tabular}{|c|c|c|c|c|c|c|}
\hline $\begin{array}{l}\text { Five-year age } \\
\text { group }\end{array}$ & $\begin{array}{l}\text { Deaths in } \\
\text { cohort with } \\
\text { coronary } \\
\text { heart disease }\end{array}$ & $\begin{array}{l}\text { Deaths in } \\
\text { 'coronary heart } \\
\text { disease cohort' } \\
\text { assuming no } \\
\text { coronary heart } \\
\text { disease }\end{array}$ & $\begin{array}{l}\text { Excess deaths } \\
\text { in coronary } \\
\text { heart disease } \\
\text { cohort }\end{array}$ & $\begin{array}{l}\text { Years of life } \\
\text { lived in cohort } \\
\text { with coronary } \\
\text { heart disease }\end{array}$ & $\begin{array}{l}\text { Years of life lived } \\
\text { in 'coronary heart } \\
\text { disease cohort' } \\
\text { assuming no } \\
\text { coronary heart } \\
\text { disease }\end{array}$ & $\begin{array}{l}\text { Years of life } \\
\text { lost (\%) }\end{array}$ \\
\hline \multicolumn{7}{|l|}{ Men } \\
\hline $15-19$ & 4088 & 2833 & 1255 & 1224943 & 1229884 & $4940(0.4)$ \\
\hline 20-24 & 4431 & 3071 & 1360 & 1242819 & 1248662 & $5843(0.5)$ \\
\hline $25-29$ & 5454 & 3779 & 1675 & 1415055 & 1422721 & 7666 (0.5) \\
\hline $30-34$ & 6898 & 4777 & 2121 & 1633531 & 1643532 & $10001(0.6)$ \\
\hline $35-39$ & 8269 & 5722 & 2547 & 1760253 & 1772034 & $11781(0.7)$ \\
\hline $40-44$ & 8683 & 6001 & 2682 & 1634313 & 1645566 & $11253(0.7)$ \\
\hline $45-49$ & 7608 & 5246 & 2362 & 1243635 & 1251409 & 7774 (0.6) \\
\hline $50-54$ & 4423 & 3039 & 1384 & 616723 & 619174 & $2451(0.4)$ \\
\hline Total & 49855 & 34468 & 15387 & 10771272 & 10832980 & $61708(0.6)$ \\
\hline \multicolumn{7}{|l|}{ Women } \\
\hline $15-19$ & 3063 & 1719 & 1344 & 1496903 & 1501921 & $5018(0.3)$ \\
\hline $20-24$ & 3438 & 1929 & 1509 & 1572218 & 1578394 & $6176(0.4)$ \\
\hline $25-29$ & 4275 & 2399 & 1876 & 1806926 & 1815158 & $8231(0.5)$ \\
\hline $30-34$ & 5362 & 3007 & 2355 & 2065574 & 2076287 & $10713(0.5)$ \\
\hline $35-39$ & 6428 & 3603 & 2825 & 2221111 & 2233807 & $12696(0.6)$ \\
\hline $40-44$ & 6781 & 3797 & 2984 & 2064460 & 2076712 & $12252(0.6)$ \\
\hline $45-49$ & 5985 & 3345 & 2640 & 1575161 & 1583732 & $8572(0.5)$ \\
\hline $50-54$ & 3549 & 1977 & 1572 & 791252 & 794019 & $2766(0.4)$ \\
\hline Total & 38881 & 21776 & 17105 & 13593606 & 13660030 & $66424(0.5)$ \\
\hline Total & 88736 & 56244 & 32492 & 24364878 & 24493010 & $128132(0.5)$ \\
\hline
\end{tabular}

Using life-table modelling, years of life lived were calculated with a half-cycle correction and an annual discount rate of $3.0 \%$. 
Table 3 Discounted QALYs in the cohort with coronary heart disease and 'hypothetically' without coronary heart disease in Indonesians aged 15-54 years, followed up until the age of 55 years

\begin{tabular}{|c|c|c|c|}
\hline $\begin{array}{l}\text { Five-year } \\
\text { age group }\end{array}$ & $\begin{array}{l}\text { QALYs lived } \\
\text { in cohort with } \\
\text { coronary heart } \\
\text { disease }\end{array}$ & $\begin{array}{l}\text { QALYs lived in } \\
\text { 'coronary heart } \\
\text { disease cohort' } \\
\text { assuming no } \\
\text { coronary heart } \\
\text { disease }\end{array}$ & QALYs lost (\%) \\
\hline \multicolumn{4}{|l|}{ Men } \\
\hline $15-19$ & 1004454 & 1120424 & $115970(10.4)$ \\
\hline $20-24$ & 1019112 & 1137531 & $118419(10.4)$ \\
\hline $25-29$ & 1160345 & 1296099 & $135753(10.5)$ \\
\hline 30-34 & 1339495 & 1497258 & 157763 (10.5) \\
\hline $35-39$ & 1443407 & 1614323 & 170915 (10.6) \\
\hline $40-44$ & 1340137 & 1499111 & $158974(10.6)$ \\
\hline $45-49$ & 1019780 & 1140033 & $120253(10.5)$ \\
\hline $50-54$ & 505713 & 564067 & 58354 (10.3) \\
\hline Total & 8832443 & 9868845 & $1036402(10.5)$ \\
\hline \multicolumn{4}{|l|}{ Women } \\
\hline $15-19$ & 1227461 & 1368250 & 140789 (10.3) \\
\hline $20-24$ & 1289218 & 1435479 & $146261(10.2)$ \\
\hline $25-29$ & 1481680 & 1653609 & $171929(10.4)$ \\
\hline $30-34$ & 1693771 & 1891497 & $197726(10.5)$ \\
\hline $35-39$ & 1821311 & 2034998 & $213687(10.5)$ \\
\hline $40-44$ & 1692857 & 1891885 & 199028 (10.5) \\
\hline $45-49$ & 1291632 & 1442780 & $151148(10.5)$ \\
\hline $50-54$ & 648827 & 723351 & 74524 (10.3) \\
\hline Total & 11146757 & 12441850 & $1295093(10.4)$ \\
\hline Total & 19979200 & 22310695 & $2331495(10.5)$ \\
\hline
\end{tabular}

QALYs, quality-adjusted life years.

Excess deaths attributable to CHD accounted for 36.6\% of all deaths among Indonesians of working age.

\section{Years of life lived}

Table 2 also summarises the years of life lived by the cohort with CHD (with follow-up until the age of 55 years), and the years of life that would have been gained had the cohort not had CHD. In total, there were 128132 years of life $(0.5 \%$ of total) lost (discounted) to CHD, with 61708 years $(0.57 \%$ of total) lost among men and 66424 years $(0.50 \%$ of total $)$ lost among women.

\section{Quality-adjusted life years}

Table 3 summarises the QALYs lived by the cohort with CHD (with follow-up until the age of 55 years), and the QALYs that would have been gained had the cohort not had CHD. In total, there were 2331495 QALYs (10.5\% of total) lost (discounted) to CHD, with 1036402 QALYs (10.5\% of total) lost among men and 1295093 QALYs (10.4\% of total) lost among women.
Table 4 Discounted PALYs in the cohort with coronary heart disease and 'hypothetically' without coronary heart disease in Indonesians aged 15-54 years, followed up until age 55 years

\begin{tabular}{|c|c|c|c|}
\hline $\begin{array}{l}\text { Five-year } \\
\text { age group }\end{array}$ & $\begin{array}{l}\text { PALYs lived } \\
\text { in cohort with } \\
\text { coronary heart } \\
\text { disease }\end{array}$ & $\begin{array}{l}\text { PALYs lived in } \\
\text { 'coronary heart } \\
\text { disease cohort' } \\
\text { assuming no } \\
\text { coronary heart } \\
\text { disease }\end{array}$ & PALYs lost (\%) \\
\hline \multicolumn{4}{|l|}{ Men } \\
\hline $15-19$ & 1080442 & 1158939 & $78497(6.7)$ \\
\hline $20-24$ & 1096210 & 1176634 & $80424(6.8)$ \\
\hline $25-29$ & 1248128 & 1340653 & 92525 (6.9) \\
\hline $30-34$ & 1440831 & 1548727 & 107896 (7.0) \\
\hline $35-39$ & 1552604 & 1669816 & $117212(7.0)$ \\
\hline $40-44$ & 1441521 & 1550643 & $109123(7.0)$ \\
\hline $45-49$ & 1096929 & 1179222 & $82294(7.0)$ \\
\hline $50-54$ & 543971 & 583457 & $39486(6.8)$ \\
\hline Total & 9500635 & 10208090 & $707456(7.0)$ \\
\hline \multicolumn{4}{|l|}{ Women } \\
\hline $15-19$ & 1320320 & 1415284 & $94964(6.7)$ \\
\hline $20-24$ & 1386750 & 1487346 & $100595(6.8)$ \\
\hline $25-29$ & 1593772 & 1710452 & $116681(6.8)$ \\
\hline $30-34$ & 1821908 & 1956518 & $134610(6.9)$ \\
\hline $35-39$ & 1959097 & 2104952 & $145855(6.9)$ \\
\hline $40-44$ & 1820925 & 1956919 & $135994(6.9)$ \\
\hline $45-49$ & 1389346 & 1492376 & $103030(7.0)$ \\
\hline $50-54$ & 697912 & 748217 & $50305(6.7)$ \\
\hline Total & 11990031 & 12872065 & $882034(6.9)$ \\
\hline Total & 21490666 & 23080156 & $1589490(6.9)$ \\
\hline
\end{tabular}

PALYs, productivity-adjusted life years.

\section{Productivity-adjusted life years}

Table 4 summarises the PALYs lived by the cohort with CHD (with follow-up until the age of 55 years), and the PALYs that would have been gained had the cohort not had CHD. In total, there were 1589490 PALYs (6.9\% of total) lost (discounted) to CHD, with 707456 PALYs (7.0\% of total) lost among men and 882034 PALYs $(6.9 \%$ of total) lost among women.

\section{Cost of productivity loss}

The cost of PALYs lost due to CHD was derived by assuming a constant GDP per full-time worker of US $\$ 11765$. Hence the total costs associated with PALYs lost to CHD was estimated to be over US $\$ 33.3$ billion (discounted), with US\$14.8 GDP lost in men and US\$18.5 GDP lost in women.

\section{Healthcare costs}

The direct annual cost of healthcare devoted to CHD in Indonesia was US $\$ 5720$ per person. Multiplying this figure by the total years of life lived amounted to total healthcare costs of US\$139 billion (discounted), with 
Table 5 Scenario analyses assessing the impact of the uncertainty surrounding key input parameters, in terms of QALYs lost, PALYs lost and GDP lost due to coronary heart disease in Indonesia

\begin{tabular}{|c|c|c|c|}
\hline Analysis & $\begin{array}{l}\text { QALYs lost owing } \\
\text { to CHD }\end{array}$ & $\begin{array}{l}\text { PALYs lost owing } \\
\text { to CHD }\end{array}$ & $\begin{array}{l}\text { GDP lots } \\
\text { (billion) US\$ }\end{array}$ \\
\hline Base case & 2331495 & 1589490 & 33.3 \\
\hline 1. Annual discount rate $1.5 \%$ & 2693568 & 1841175 & 41.1 \\
\hline$\%$ change compared with base case & +15 & +15 & +23 \\
\hline $\begin{array}{l}\text { 2. Lower uncertainty bound for } \mathrm{RR} \text { of all-cause mortality applicable } \\
\text { to people with } \mathrm{CHD} \text { (male: } \mathrm{RR}=1.32 \text {; female: } \mathrm{RR}=1.6 \text { ) }\end{array}$ & 2302773 & 1558620 & 32.5 \\
\hline$\%$ change compared with base case & -1.2 & -2.0 & -2.5 \\
\hline $\begin{array}{l}\text { 3. Upper uncertainty bound for } \mathrm{RR} \text { of all-cause mortality applicable } \\
\text { to people with } \mathrm{CHD} \text { (male: } \mathrm{RR}=1.62 \text {; female: } \mathrm{RR}=2.02 \text { ) }\end{array}$ & 2363435 & 16238818 & 34.2 \\
\hline$\%$ change compared with base case & +1.4 & +2.2 & +2.8 \\
\hline 4. Increasing by $15 \%$ the total number of days missed out of work & & 2020621 & 42.1 \\
\hline$\%$ change compared with base case & & +27 & +26.4 \\
\hline 5. No temporal trend in GDP & & & 18.6 \\
\hline$\%$ change compared with base case & & & -44 \\
\hline 6. Annual GDP growth rate halved to $2.58 \%$ & & & 24.4 \\
\hline$\%$ change compared with base case & & & -26.7 \\
\hline \multicolumn{4}{|l|}{ Reducing prevalence } \\
\hline 7. Prevalence of $\mathrm{CHD}$ reduced by $25 \%$ & 1748826 & 1192355 & 25.0 \\
\hline$\%$ change compared with base case & -25 & -25 & -25 \\
\hline 8. Prevalence of $\mathrm{CHD}$ reduced by $50 \%$ & 1166022 & 795063 & 16.6 \\
\hline$\%$ change compared with base case & -50 & -50 & -50 \\
\hline
\end{tabular}

CHD, coronary heart disease; GDP, gross domestic product; PALYs, productivity-adjusted life years; QALYs, quality-adjusted life years; RR, relative risk.

US $\$ 61$ billion incurred among men and US\$77billion incurred among women. These would be cost savings to the Indonesian healthcare system if, hypothetically, CHD did not exist.

\section{Scenario analyses}

The model was sensitive to a number of assumptions as illustrated in table 5. For example, applying the lower and upper bounds of the RR of all-cause mortality associated with CHD, decreased the number of PALYs lost by $2.0 \%$ and increased them by $2.2 \%$, respectively. Reducing the discounting rate from $3.0 \%$ to $1.5 \%$, increased the number of PALYs lost by $15 \%$. Similarly, increasing the total annual number missed workdays (absenteeism and presenteeism) from 21.8 days to 25.07 days, increased the number of PALYs lost by $27 \%$. Whereas, removing the temporal trend in GDP growth, reduced PALYs lost by $44 \%$.

\section{DISCUSSION}

Our study suggests that CHD is likely to impose a significant impact on the future health and productivity of the Indonesian population. Because we focused on the working age population in Indonesia, the estimates exclude the burden borne by people older than 55 years (retirement age), which would be even greater. The results were most sensitive to the discounting rate and trends in annual GDP growth.

Impact of coronary heart disease on mortality and quality of life

The findings of our study are not directly comparable to those of any other study because no other study has estimated the mortality and morbidity burden of CHD among Indonesians across the timeframe of working age. Rather, other Indonesian studies have estimated the burden of CHD in a cross-sectional (as opposed to a longitudinal) manner. While some studies from other countries have estimated the burden of CHD in a longitudinal manner, few have focused on the burden specifically among people of working age.

Although the average burden of CHD among Indonesians of working age is small, arising from a low prevalence of the condition in the age group, the burden at a national level is high given the size of the Indonesian population. Our study estimated that reducing the prevalence CHD by $50 \%$ among Indonesians of working age would lead to gains of 64470 years of life and 1166022 QALYs. By any measure, this is a significant amount of time incurred by people who would otherwise drive the economy of Indonesia. 


\section{Impact of coronary heart disease on productivity}

PALYs are a newly derived measure, having been described in 2018 by Magliano et al in the setting of diabetes. ${ }^{10}$ To date, they have been used to estimate the productivity impact of diabetes, smoking and hypertension, ${ }^{9-11} 25$ but not CHD, and not for any condition in an Indonesian setting, this further underpins the novelty of our work.

We estimated that among Indonesians aged $15-54$ years who currently have CHD, US $\$ 33.3$ billion would be lost in GDP by the time the cohort members all reach age 55 years.

A study by Song et al conducted in the US estimated the costs of CHD-related events among full-time employees aged 18-65 years within a 9-year timeframe (2002-2011). ${ }^{5}$ The study estimated costs due to workplace absenteeism for a total of 38229 patients who experienced CHD and related events. After the first-year follow-up, the costs were equivalent to US $\$ 698$ per person, among 3370 patients.

A study in Australia estimated the indirect costs of CHD in 6700 workers aged 45-64 years through productive life years lost within a 15-year timeframe (2015-2030). ${ }^{26}$ By 2030, the population was projected to reach 8100 . The total cost of GDP, after a 15-year follow-up, was US $\$ 1.1$ billion. These costs were equivalent to US $\$ 133$ 580 per person over this period.

The findings of USA and Australian studies are not directly comparable to those of our study because of differences in simulated periods of follow-up, assumptions and approaches used in the modelling and data inputs (especially the prevalence of CHD and the economic value of each worker). Nevertheless, they all share the same conclusion: that CHD exerts a significant impact on the broader economy of a country. Despite the low prevalence of CHD in Indonesia relative to western countries, its effect on GDP is still considerable.

\section{Impact of coronary heart disease on healthcare costs}

We assumed that each Indonesian of working age with CHD would incur US $\$ 5270$ in healthcare costs per year. ${ }^{24}$ Multiplying this annual cost by the predicted years of life lived by Indonesians aged 15-54 years who currently have CHD, until age 55 years, led to the estimation that US $\$ 139$ billion would be spent on healthcare costs specifically for the condition.

Estimates from around the world of the direct healthcare costs of CHD vary considerably. A study by Liu et al, ${ }^{27}$ in the UK estimated that costs per person per year were US $\$ 832$ in 1999, while a study by Tarride et $a{ }^{28}$ in the US estimated the cost to be US\$25 035 in the period from 1998 to 2006. In between these two estimates, a study from South Korea estimated that the cost was US\$1982 in $2016 .{ }^{29} \mathrm{~A}$ recent systematic review on the economic burden of cardiovascular disease in low-income andmiddle-income countries by Gheorghe et al suggested that monthly economic costs for stroke and CHD varied between Int $\$ 300$ and Int $\$ 1000$ but these studies were considered to be lacking in methodological detail. ${ }^{30}$
It would be inappropriate to compare estimates of healthcare costs across countries given the variability of healthcare systems in different markets, including the extent to which they are publicly and privately funded. Furthermore, costing studies themselves vary in terms of assumptions and types of costs counted. Therefore, similar work needs to be performed in other countries to explore this generalisability.

We estimated that by reducing the prevalence of CHD by $50 \%$, US $\$ 69$ billion would be saved. This would contribute even more to the economy. However, even if we had over-estimated the annual healthcare costs of CHD, predicted future expenditure for Indonesians of working age is likely to be very large. This provides further rationale for strategies for controlling CHD in Indonesia.

\section{Indonesian policies for controlling coronary heart disease}

Across the world, there have been many educational interventions targeting CHD, and cardiovascular disease more generally. In Indonesia specifically, the Ministry of Health has implemented several policies. ${ }^{31}$ This includes Cek kesehatan secara berkala, Enyahkan asap rokok, Rajin beraktifitas fisik, Diet yang sehat dan seimbang, Istirahat yang cukup dan Kelola stres, Instruksi Presiden Nomor 1 with Gerakan Masyarakat Hidup Sehat being part of it and Pos Pembinaan Terpadu untuk Penyakit Tidak Menular. ${ }^{31}$

Despite the many initiatives launched in Indonesia, there remain significant unaddressed healthcare needs, and this is due to several factors. First, there is a severe workforce shortage and a lack of adequate infrastructure. $^{3}$ Therefore, many Indonesians seek healthcare elsewhere, costing US $\$ 4.0$ billion each year. ${ }^{3}$

Second, there is a significant uneven distribution of healthcare facilities across the Indonesian archipelago of over 17000 islands. This has led to a 15-year difference in life expectancy between people from urban and rural areas. Compounding this inequity is a wide income distribution, as well as multiple levels of government and administration that highlight Indonesia's geographical healthcare challenge. ${ }^{3}$

Finally, healthcare providers and the healthcare industry are not incentivised to achieve and maintain levels of quality and access, with few systematic processes to benchmark against global standards in healthcare. ${ }^{3}$

However, there is an appetite for change, and Indonesian's healthcare system is currently undergoing major reform, starting with the adoption in 2014 of a universal funding.

Our study provides important data that will help shape the Indonesian healthcare system as it continues to evolve. It is useful that the impact of CHD, and other major chronic diseases, be couched in broader economic terms, especially as chronic diseases take on increasing prominence in the disease landscape of Indonesia (as in most low to middle-income countries). The modelling methods that were used in the present study are 
applicable to any chronic disease, as long as equivalent data inputs are available.

Ultimately, clinical and public health evidence-based strategies to control CHD should be viewed as investments for the Indonesian health system, as opposed to expenditures.

\section{Strengths and limitations}

Estimating the impact of CHD on productivity in terms of PALYs is novel and informative, especially in Indonesia. By using PALYs, we estimated the 'true cost' CHD, considering its impact on the larger economy. PALYs provide a wider perspective on the impact of disease, and help inform public health strategies on prevention, early detection and treatment.

There are limitations to our study that warrant mention. First, despite that life table modelling is commonly used in demographical and epidemiological studies, it has several limitations. One such limitation is known as the life table assumption, in which agespecific mortality is assumed to not change over time. However, as the life table assumption was applied to both the cohort with and without CHD, its effect on the study results was minimised.

A second limitation relates to the fact that although CHD could not be totally eliminated, its prevalence may change over time. Data on projected prevalence were not available, hence it was assumed to remain constant within the timeframe of the study. This may have led to inaccurate estimations of the number of people with CHD and the future burden it is likely to impose.

Thirdly, the utilities and productivity indices used in our study were potentially imprecise and was not specified according to the type of work that people do. It is likely that the impact of CHD on productivity differs across different jobs, being more likely to impair people undertaking physical work. Furthermore, the number of days lost due to absenteeism and presenteeism as a result of CHD were based on data from USA, as none were available from Indonesia. The number of days lost may differ between USA and Indonesia. Also, data regarding the RR for all-cause death conferred by CHD were drawn from a study conducted in Denmark, given the lack of Indonesian data. These limitations may have led to inaccuracy in the estimation of the productivity burden of CHD in Indonesia, but they would not have changed the overall conclusion that this burden is very high.

Lastly, the present study assumed that future annual GDP growth would increase by $5.17 \%$, while in future, this number may change over time. Hence, this study may have over predicted the economic burden of CHD in Indonesia. However, even when no GDP trends were applied, this study predicted there would be US $\$ 18.6$ billion in lost GDP due to reduced productivity, highlighting the significant work productivity burden of CHD.

\section{CONCLUSION}

The health and economic burden of CHD in Indonesia looms large. This highlights the importance of early detection, its prevention and control, treatment strategies for which, if effective, will deliver a financial return.

Twitter Dianna Magliano @diannamagliano and Zanfina Ademi @ZANFINA

Contributors DL, ZA and DM conceived the idea and contributed to the design of the work. REU, ZA and RPUS contributed to the acquisition, analysis or interpretation of data for the work. REU and ZA drafted the manuscript. ZA, DL, DM, RPUS and EZ critically revised the manuscript. All authors gave final approval and agree to be accountable for all aspects of the work ensuring integrity and accuracy.

Funding The authors have not declared a specific grant for this research from any funding agency in the public, commercial or not-for-profit sectors.

\section{Competing interests None declared.}

Patient and public involvement Patients and/or the public were not involved in the design, or conduct, or reporting, or dissemination plans of this research.

Patient consent for publication Not required.

Provenance and peer review Not commissioned; externally peer reviewed.

Data availability statement Data are available upon reasonable request. The model is available upon reasonable request to the authors.

Open access This is an open access article distributed in accordance with the Creative Commons Attribution Non Commercial (CC BY-NC 4.0) license, which permits others to distribute, remix, adapt, build upon this work non-commercially, and license their derivative works on different terms, provided the original work is properly cited, appropriate credit is given, any changes made indicated, and the use is non-commercial. See: http://creativecommons.org/licenses/by-nc/4.0/.

ORCID iD

Zanfina Ademi http://orcid.org/0000-0002-0625-3522

\section{REFERENCES}

1 Roser M, Ritchie H. Burden of disease. Institute for health metrics and evaluation, 2018. Available: https://ourworldindata.org/burdenof-disease

2 McAloon CJ, Boylan LM, Hamborg T, et al. The changing face of cardiovascular disease 2000-2012: an analysis of the world health organisation global health estimates data. Int $J$ Cardiol 2016;224:256-64.

$3 \mathrm{Lim}$ J, Sharma S, Colyer T, et al. The future of the Indonesian healthcare ecosystem: the outlook to 2030. Oliver Wyman 2018:4-5.

4 Rasmussen B, Sweeny K, Sheehan P. Economic costs of absenteeism, presenteeism and early retirement due to ill health: a focus on Indonesia. Victoria Institute of Strategic Economic Studies 2016:1-7

5 Song X, Quek RGW, Gandra SR, et al. Productivity loss and indirect costs associated with cardiovascular events and related clinical procedures. BMC Health Serv Res 2015;15:245.

6 Kotseva K, Gerlier L, Sidelnikov E, et al. Patient and caregiver productivity loss and indirect costs associated with cardiovascular events in Europe. Eur J Prev Cardiol 2019;26:1150-7.

7 Indonesian Health Technology Assessment Committee (InaHTAC), Ministry of Health of the Republic of Indonesia. Health technology assessment (HTa) guideline. Available: http://adphealth.org/upload/ resource/FINAL_HTA_ENG_1.pdf [Accessed 23 Jun 2020].

8 Hird T, Zommer E, Owen A, et al. Productivity burden of hypertension in Australia: a life table modeling study. American Heart Association 2019:2.

9 Hird T, Zommer E, Owen A. The impact of diabetes on productivity in China. Springer, 2019: 2.

10 Magliano D, Martin V, Owen A, et al. The productivity burden of diabetes at a population level. American Diabetes Association 2018:2.

11 Owen AJ, Maulida SB, Zomer E, et al. Productivity burden of smoking in Australia: a life table modelling study. Tob Control 2019;28:1.

12 Ounsirithupsakul T, Dilokthornsakul P, Kongpakwattana K, et al. Estimating the productivity burden of pediatric pneumococcal disease in Thailand. Appl Health Econ Health Policy 2020;18:579-87. 
13 Institute for Health Metrics and Evaluation (IHME). Global burden of disease study 2017: population estimates, 2018. Available: http:// ghdx.healthdata.org/record/ihme-data/gbd-2017-populationestimates-1950-2017

14 Institute for Health Metrics and Evaluation (IHME). Global burden of disease study 2017 (GBD 2017) results, 2017. Available: http:// vizhub.healthdata.org/gbd-compare/

15 Ministry of Health Republic of Indonesia. National Institute for Health Research \& Development. Riset Kesehatan Dasar (National Health Survey) 2018.

16 Norgaard ML, Andersen SS, Schramm TK, et al. Changes in short- and long-term cardiovascular risk of incident diabetes and incident myocardial infarction--a nationwide study. Diabetologia 2010;53:1612-9.

17 Purba F, Hunfeld J, Iskandarsyah A, et al. Test-Retest reliability and population norms of the EQ-5D-5L and WHOQOL-BREF 2018:8.

18 Tran BX, Moir MP, Thai TPT, et al. Socioeconomic inequalities in health-related quality of life among patients with cardiovascular diseases in Vietnam. Biomed Res Int 2018;2018:1-8.

19 Goetzel RZ, Long SR, Ozminkowski RJ, et al. Health, absence, disability, and presenteeism cost estimates of certain physical and mental health conditions affecting U.S. employers. J Occup Environ Med 2004;46:398-412.

20 Johns G. Attendance dynamics at work: the antecedents and correlates of presenteeism, absenteeism, and productivity loss. $J$ Occup Health Psychol 2011;16:483-90.

21 Labour force situation in Indonesia. Badan Pusat Statistik (Indonesian Bureau of statistics) 2018.
22 International Monetary Fund. Gross domestic product in Indonesia, 2019. Available: https://www.imf.org/external/pubs/ft/weo/2017/02/ weodata/weorept.aspx?pr. $\mathrm{x}=21 \&$ pr.y $=9 \&$ sy $=2015 \&$ ey $=2022 \&$ scsm $=$ $1 \& s s d=1 \&$ sort $=$ country\&ds $=. \& b r=1 \& c=536 \& s=N G D P D \& g r p=0 \& a=$

23 The world bank data. available through. Available: https://data. worldbank.org/indicator/NY.GDP.MKTP.KD.ZG?locations=ID

24 Indonesian Case Base group (INACBG). Kementerian Kesehatan (Ministry of health) 2018.

25 Tan QY, Zomer E, Owen AJ, et al. Impact of tobacco use on health and work productivity in Malaysia. Tob Control 2020;29:2.

26 Schofield D, Cunich M, Shrestha R, et al. The indirect costs of ischemic heart disease through lost productive life years for Australia from 2015 to 2030: results from a microsimulation model. BMC Public Health 2019;19:8-10.

27 Liu JLY, Maniadakis N, Gray A, et al. The economic burden of coronary heart disease in the UK. Heart 2002;88:597-603.

28 Tarride J-E, Lim M, DesMeules M, et al. A review of the cost of cardiovascular disease. Can J Cardiol 2009;25:e195-202.

29 The Economist Intelligence Unit. The cost of silence: cardiovascular disease in Asia 2018:4.

30 Gheorghe A, Griffiths U, Murphy A, et al. The economic burden of cardiovascular disease and hypertension in low- and middle-income countries: a systematic review. BMC Public Health 2018;18:975 https://doi.org/

31 Kementerian Kesehatan Republik Indonesia (Ministry of Health Republic of Indonesia). Penyakit jantung penyebab kematian tertinggi, kemenkes ingatkan CERDIK, 2017. Available: http://www. depkes.go.id/article/view/17073100005/penyakit-jantung-penyebabkematian-tertinggi-kemenkes-ingatkan-cerdik-.html 